\title{
Behaviour of advanced tritium breeder pebbles under simultaneous action of accelerated electrons and high temperature
}

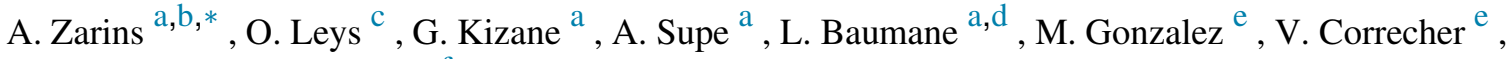 \\ C. Boronat ${ }^{\mathrm{e}}$, A. Zolotarjovs ${ }^{\mathrm{f}}$, R. Knitter ${ }^{\mathrm{c}}$ \\ ${ }^{a}$ University of Latvia, Institute of Chemical Physics, Jelgavas street 1, LV-1004, Riga, Latvia \\ ${ }^{\mathrm{b}}$ Daugavpils University, Faculty of Natural Science and Mathematics, Department of Chemistry and Geography, Parades street 1a, Daugavpils, LV-5401, Latvia \\ ${ }^{c}$ Karlsruhe Institute of Technology, Institute for Applied Materials (IAM-KWT), 76021, Karlsruhe, Germany ${ }^{\mathrm{d}}$ \\ Latvian Institute of Organic Synthesis, Aizkraukles street 21, LV-1006, Riga, Latvia \\ ${ }^{\mathrm{e}}$ LNF-CIEMAT, Materials for Fusion Group, Av. Complutense 40, 28040, Madrid, Spain \\ ${ }^{\mathrm{f}}$ University of Latvia, Institute of Solid State Physics, Kengaraga street 8, LV-1063, Riga, Latvia
}

highlights

- Irradiation temperature affects accumulation of radiation-induced defects (RD) and radiolysis products (RP)

- With an increasing content of $\mathrm{Li}_{2} \mathrm{TO}_{3}$ in the advanced pebbles, the concentration of accumulated RD and RP decreases.

- The accumulated RD and RP annihilates around 423-773 K.

- Mechanical properties of the advanced pebbles practically do not change after irradiation.

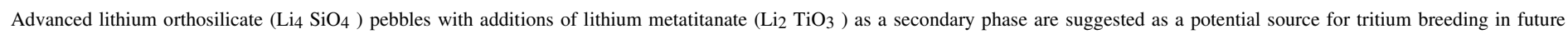

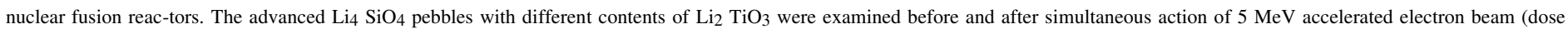

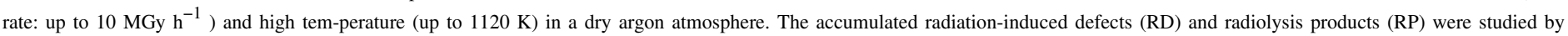

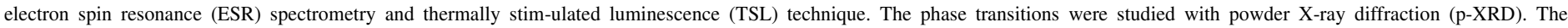

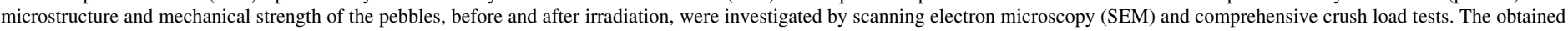

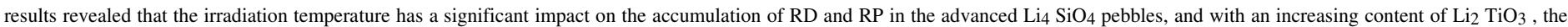

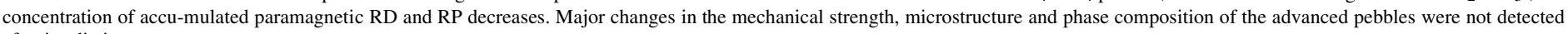
after irradiation.

\section{Introduction}

Lithium orthosilicate ( $\left.\mathrm{Li}_{4} \mathrm{SiO}_{4}\right)$ and lithium metatitanate $\left(\mathrm{Li}_{2} \mathrm{TiO}_{3}\right)$ in the form of ceramic pebbles have been developed as two of the most promising tritium breeder candidates for future nuclear fusion reactors [1]. Under the operation conditions of the fusion reactors, the tritium breeder pebbles will be exposed to an intense neutron fluence (up to $10^{18} \mathrm{n} \mathrm{m}^{-2} \mathrm{~s}^{-1}$ ), a high temperature (up to $1193 \mathrm{~K}$ ) and a magnetic field (up to 7-10 T) [2]. The latest results of the post-irradiation examination [3] confirmed that both tritium breeder pebbles will perform sufficiently well under the expected operation conditions. However, it has also been reported that the mechanical properties of pure $\mathrm{Li} 4 \mathrm{SiO} 4$ pebbles need to be improved, while $\mathrm{Li} 2 \mathrm{TiO} 3$ pebbles require a higher enrichment with lithium-6, to increase tritium production. 
Specification of the investigated advanced $\mathrm{Li}_{4} \mathrm{SiO}_{4}$ pebbles with different contents of $\mathrm{Li}_{2} \mathrm{TiO}_{3}$ and the reference pebbles.

\begin{tabular}{|c|c|c|c|c|c|c|}
\hline \multirow[t]{2}{*}{ Sample } & \multirow[t]{2}{*}{ Pebbles } & \multicolumn{3}{|c|}{ Phase compositions } & \multirow[t]{2}{*}{ Pebble size ( $\mathrm{m}$ ) } & \multirow[t]{2}{*}{ Description } \\
\hline & & $\mathrm{Li}_{4} \mathrm{SiO}_{4}, \mathrm{~mol} \%$ & $\mathrm{Li}_{2} \mathrm{TiO}_{3}, \mathrm{~mol} \%$ & $\mathrm{Li}_{2} \mathrm{SiO}_{3}, \mathrm{~mol} \%$ & & \\
\hline$\# 0$ & Reference & 90 & 0 & 10 & $\begin{array}{l}500 \\
650-900\end{array}$ & $\begin{array}{l}\text { Un-treated } \\
\text { Thermally pre-treated }\end{array}$ \\
\hline$\# 1$ & Advanced & 90 & 10 & 0 & $\begin{array}{l}1000 \\
650-900\end{array}$ & $\begin{array}{l}\text { Un-treated } \\
\text { Thermally pre-treated }\end{array}$ \\
\hline$\# 2$ & Advanced & 80 & 20 & 0 & $\begin{array}{l}500 \\
650-900\end{array}$ & $\begin{array}{l}\text { Un-treated } \\
\text { Thermally pre-treated }\end{array}$ \\
\hline$\# 3$ & Advanced & 75 & 25 & 0 & 500 & Un-treated \\
\hline$\# 4$ & Advanced & 70 & 30 & 0 & $\begin{array}{l}500 \\
650-900\end{array}$ & $\begin{array}{l}\text { Un-treated } \\
\text { Thermally pre-treated }\end{array}$ \\
\hline \#5 & Advanced & 60 & 40 & 0 & 1000 & Thermally pre-treated \\
\hline
\end{tabular}

The advanced $\mathrm{Li}_{4} \mathrm{SiO}_{4}$ pebbles with additions of $\mathrm{Li}_{2} \mathrm{TiO}_{3}$ as a secondary phase have been proposed as an alternative candidate for the tritium breeding [4]. The optimum content of $\mathrm{Li}_{2} \mathrm{TiO}_{3}$ has yet to be evaluated; nonetheless the advanced pebbles have enhanced mechanical properties, without losing the benefit of a high lithium density and melting temperature [5]. The preliminary studies indi-cate that the change in the chemical composition of the pebbles does not significantly affect the radiation stability [6], release char-acteristics [7] and activation behaviour [8]. The re-melting and lithium re-enrichment studies [9] also revealed that the recycling of the advanced breeder pebbles, without a deterioration of the mate-rial properties, is possible using an enhanced melt-based process.

However, to develop a new two-phase composition for the tri-tium breeder pebbles, it is a critical issue to study the behaviour of the advanced

$\mathrm{Li} 4 \mathrm{SiO}_{4}$ pebbles under the simultaneous action of radiation, temperature and magnetic field. From previous long-term irradiation studies [10,11], it is known that under such conditions various physicochemical processes (lithium burn-up, atomic displacements, radiation-induced chemical processes and phase transitions) can take place and thus affect the phase compo-sition and microstructure, as well as the thermal and mechanical properties of the breeder pebbles. The accumulated radiation-induced defects (RD) and radiolysis products (RP) may interact with generated tritium and strongly influence the tritium transport and release processes [12-14]. Previously, the correlation between the tritium release processes and the thermal annealing of RD and RP have been detected [15] and it has been assumed that the recombination of RD and RP could trigger the tritium detrapping.

We herein report on the behaviour of the advanced $\mathrm{Li} 4 \mathrm{SiO} 4$ pebbles with various contents of $\mathrm{Li}_{2} \mathrm{TiO}_{3}$ considering simultaneous action of $5 \mathrm{MeV}$ accelerated electron beam (dose rate: up to $10 \mathrm{MGy}^{-1}$ ) and high temperature (up to $1120 \mathrm{~K}$ ) in dry argon atmosphere, to predict the tritium diffusion and release mechanisms. Such study was performed by means of electron spin resonance (ESR), pow-der X-ray diffraction (p-XRD), thermally stimulated luminescence (TSL) and scanning electron microscopy (SEM) techniques and, as a preliminary approach, only the flux of accelerated electrons was used instead of neutron irradiation, to introduce RD and RP while avoiding nuclear reactions and thereby the formation of radioactive isotopes. The irradiation temperature was chosen in order to reach conditions comparable to the operation conditions of the fusion nuclear reactor.

\section{Experimental}

The advanced $\mathrm{Li}_{4} \mathrm{SiO}_{4}$ pebbles with five different contents of $\mathrm{Li}_{2} \mathrm{TiO}_{3}$ were selected for this research together with the reference pebbles (Table 1). The reference pebbles $\left(0 \mathrm{~mol} \% \mathrm{Li}_{2} \mathrm{TiO}_{3}\right)$ consist of two main phases - $\mathrm{Li} 4$ $\mathrm{SiO}_{4}$ as the primary and lithium metasil-icate $\left(\mathrm{Li}_{2} \mathrm{SiO}_{3}\right)$ as a secondary phase, and they are the present reference material for tritium breeding in the EU developed con- cept [1]. The advanced pebbles were produced by an enhanced melt-based process at the Karlsruhe Institute of Technology (Karl-sruhe, Germany) [4], while the reference pebbles were fabricated by a melt-spraying method at Schott AG (Mainz, Germany) [16]. To achieve an operation relevant microstructure, the fabricated advanced and reference pebbles were thermally pre-treated at $1223 \mathrm{~K}$ for $504 \mathrm{~h}$ in air.

Both, the un-treated and thermally pre-treated $\mathrm{Li} 4 \mathrm{SiO} 4$ peb-bles with different contents of $\mathrm{Li}_{2} \mathrm{TiO}_{3}$ were encapsulated in quartz tubes with a dry argon and were irradiated with the linear electron accelerator ELU-4 (Salaspils, Latvia), up to $4 \mathrm{~h}$ per day (Table 2). During one irradiation campaign (three irradiation cycles) with $5 \mathrm{MeV}$ accelerated electrons, up to $100 \mathrm{MGy}$ absorbed dose (dose rate: $<10 \mathrm{MGy} \mathrm{h}^{-1}$ ), up to four quartz tubes were irradiated simul-taneously. The electron beam diameter is around $40 \mathrm{~mm}$ and to avoid differences in the absorbed dose depending on tube loca-tion in the irradiation area, the location of each tube was changed after each irradiation cycle. Due to the collision of accelerated elec-trons with quartz tubes and pebbles, most of the kinetic energy of the accelerated electrons is transferred into heat within the speci-men, causing a local temperature rise (up to $1120 \mathrm{~K}$ ). Therefore, the irradiation temperature was continuously measured by a chromel-alumel thermocouple, that was located in central part of irradiated area, with an Agilent 34970 A multichannel digital voltmeter and an Agilent 34902 A multiplexer and recorded with a PC using the Agi-lent BenchLink Data Logger 3 software. The measured temperature differences between separate irradiation cycles could be associated with beam center displacement, linear electron accelerator current or voltage changes etc.

The accumulated paramagnetic RD and RP were investigated by ESR spectrometry. The ESR spectra were recorded using Bruker BioSpin X-band ESR spectrometer (microwave frequency: $9.8 \mathrm{GHz}$, microwave power: 0.2 $\mathrm{mW}$, modulation amplitude: $5 \mathrm{G}$, field sweep: 200 and $1000 \mathrm{G}$ ) operating at room temperature. The pebbles were analysed in ER 221TUB/3 CFQ quality tubes with a diameter of $3 \mathrm{~mm}$, both before and after irradiation. The reference marker ER 4119HS-2100 (g-factor: $1.9800 \pm 0.0005$, radical concentration: $1.15^{\bullet} 10^{-3} \%$ ) was used for quantitative measurements.

The thermal stability and recombination of accumulated RD and RP were studied by TSL technique. The TSL glow emission, observed through a blue filter (a FIB002 of the Melles-Griot Com-pany), was carried out using an automated Risø TL reader model TL DA-12 with an EMI 9635 QA photomultiplier. The reader is pro-vided with a ${ }^{90} \mathrm{Sr} /{ }^{90} \mathrm{Y}$ beta source with a dose rate of $0.011 \mathrm{~Gy} \mathrm{~s}^{-1}$ calibrated against a ${ }^{137} \mathrm{Cs}$ gamma source in a secondary standard laboratory. The samples were measured using a linear heating rate of $5 \mathrm{~K} \mathrm{~s}^{-1}$ from room temperature up to $773 \mathrm{~K}$ in a nitrogen atmosphere. To acquire information about spectral distribution of TSL, another experimental setup was used: Andor Shamrock B-303i spectrograph equipped with a CCD camera Andor DU-401A-BV with different cryostats: from nitrogen cryostat to high-power 
Specification of irradiation conditions of the advanced and the reference $\mathrm{Li}_{4} \mathrm{SiO}_{4}$ pebbles with $5 \mathrm{MeV}$ accelerated electrons (D - absorbed dose, $\mathrm{P}$ - dose rate, $\mathrm{T}$ - irradiation temperature).

\begin{tabular}{|c|c|c|c|c|c|c|c|}
\hline Sample & Description & D, MGy & $\mathrm{P}, \mathrm{MGy} \mathrm{h}^{-1}$ & $\mathrm{~T}_{\text {(cycle) }}, \mathrm{K}$ & $\mathrm{T}_{\text {(aver.) }}, \mathrm{K}$ & $\mathrm{T}_{(\min )}, \mathrm{K}$ & $\mathrm{T}_{\text {(max) }}, \mathrm{K}$ \\
\hline $\begin{array}{l}\# 0 ; \# 1 ; \# 2 ; \\
\# 4\end{array}$ & Un-treated & 100 & $<10$ & $\begin{array}{l}\text { (1) } 850-930 \\
\text { (2) } 1010-1120 \\
\text { (3) } 770-900\end{array}$ & 920 & 770 & 1120 \\
\hline $\begin{array}{l}\# 0 ; \# 1 ; \# 2 ; \\
\# 4\end{array}$ & $\begin{array}{l}\text { Thermally } \\
\text { pre-treated }\end{array}$ & 100 & $<10$ & $\begin{array}{l}\text { (1) } 580-640 \\
\text { (2) } 700-770 \\
\text { (3) } 820-840\end{array}$ & 710 & 580 & 840 \\
\hline $\begin{array}{l}\# 3 \\
\# 5\end{array}$ & $\begin{array}{l}\text { Un-treated } \\
\text { Thermally } \\
\text { pre-treated }\end{array}$ & 100 & $<10$ & $\begin{array}{l}\text { (1) } 790-950 \\
\text { (2) } 780-860 \\
\text { (3) } 500-540\end{array}$ & 730 & 500 & 950 \\
\hline
\end{tabular}

heating element providing temperature range $8-700 \mathrm{~K}$ with vari-able heating rate $\left(2 \mathrm{~K} \mathrm{~s}^{-1}\right.$ used).

The phase transitions and microstructural changes after irra-diation were studied by $\mathrm{p}$-XRD and SEM respectively. The $\mathrm{p}$-XRD patterns were obtained by a Bruker D8 (range: $15-70^{\circ}$ 2theta, scan speed: $0.02^{\circ}$ 2theta, step time: $5 \mathrm{~s}$, source: $\mathrm{CuK}$ ). The fol-lowing datasets were used from the JCPDS PDF-2 (Release 2010) database: $\mathrm{Li}_{4} \mathrm{SiO}_{4}-074-0307, \mathrm{Li} 2 \mathrm{SiO} 3-029-0828$ and $\mathrm{Li}_{2}$ $\mathrm{TiO}_{3}-033-0831$. The microstructure of the pebbles was examined at etched cross-sections with a field emission SEM (SUPRA 55, Zeiss).

The mechanical properties of the pebbles were analysed by per-forming compressive crush load tests before and after irradiation. 40 single monosized pebbles (diameter: 500 or $1000 \mathrm{~m}$ ) were measured individually by a Zwick-Roell UTS electro-mechanical testing system. This method involves a continuously increasing load imposed onto single pebbles between sapphire plates until they break, after which the mean crush load was determined. Before the crush load test measurements, the pebbles were dried at $573 \mathrm{~K}$ for one hour in a nitrogen atmosphere to remove any moisture present.

\section{Results and discussion}

The un-treated and thermally pre-treated advanced $\mathrm{Li} 4 \mathrm{SiO} 4$ pebbles with additions of $\mathrm{Li}_{2} \mathrm{TiO}_{3}$ as a secondary phase show an off-white colour - pale yellow, pink, purple or brown, before irra-diation. During thermal pretreatment slight changes from initial colour of the pebbles have been observed. It has been assumed that the colour might be caused by a redox reaction due to the presence of metallic impurities, added in the pebbles during the fabrication process or by the raw materials [9] associated, for example, with the reduction of $\mathrm{Ti}^{4+}$ ions or formation of oxygen vacancies during the fabrication process. Using $\mathrm{p}-\mathrm{XRD}$, it has been determined that the un-treated advanced pebbles have two main crystalline phases

- monoclinic $\mathrm{Li}_{4} \mathrm{SiO}_{4}$ as the primary phase and monoclinic $\mathrm{Li}_{2} \mathrm{TiO}_{3}$ as the secondary phase (Fig. 1). No traces of ternary compounds, such as, $\mathrm{Li}_{2}$ TiSiO5 [17], or chemisorption products, such as, lithium hydroxide ( $\mathrm{LiOH})$ or carbonate $\left(\mathrm{Li}_{2} \mathrm{CO}_{3}\right)$, were detected. After ther-mal pre-treatment, the diffraction peaks of $\mathrm{Li}_{4} \mathrm{SiO}_{4}$ and $\mathrm{Li}_{2} \mathrm{TiO}_{3}$ becomes higher and narrower, due to the increase in crystallinity.

In the advanced pebbles, both phases $\left(\mathrm{Li}_{4} \mathrm{SiO}_{4}\right.$ and $\left.\mathrm{Li}_{2} \mathrm{TiO}_{3}\right)$ are fully separated [5] and it is anticipated that the mechanisms and the structure of the formed RD and RP during irradiation with $5 \mathrm{MeV}$ accelerated electrons will be similar to single phase ceramics. Previ-ously, the formation and accumulation of $\mathrm{RD}$ and $\mathrm{RP}$ in $\mathrm{Li}_{4} \mathrm{SiO}_{4}$ and $\mathrm{Li}_{2} \mathrm{TiO}_{3}$ ceramics under the action of neutron fluence, accelerated electrons and gamma rays have been investigated and described separately by several authors [18-25]. The formation and accu-mulation of RD and RP takes place through two stages: (1) fast generation of primary RD and RP on structural defects and impurities, and (2) slow generation due to the radiolysis of the basic matrix. As soon as the structural defects have been consumed, the

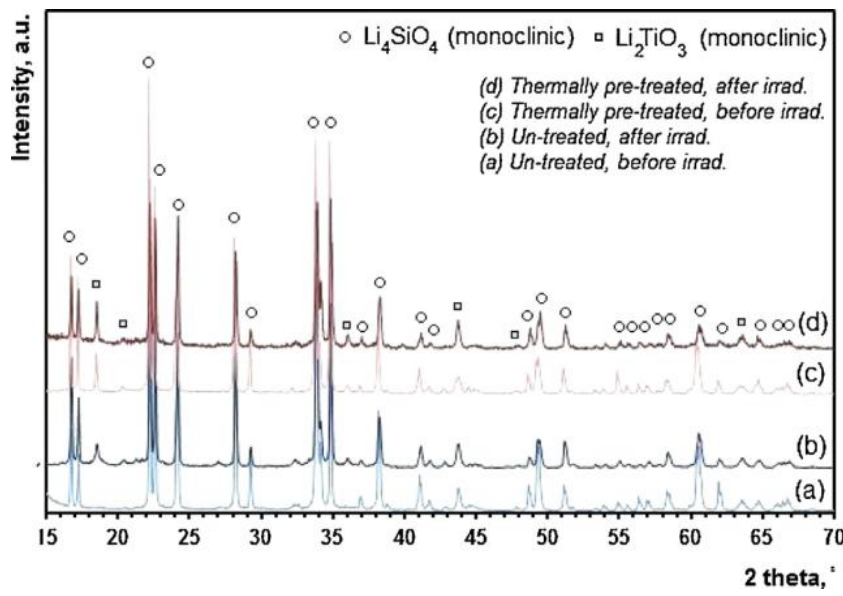

Fig. 1. p-XRD pattern of the un-treated and thermally pre-treated advanced $\mathrm{Li}_{4} \mathrm{SiO}_{4}$ pebbles with $10 \mathrm{~mol} \% \mathrm{Li} 2 \mathrm{TiO} 3$ before and after irradiation with $5 \mathrm{MeV}$ accelerated electrons up to 100 MGy absorbed dose at 500-1120 K in a dry argon atmosphere.

formation of RD and RP occurs only at the crystalline lattice. The thermal pretreatment decreases the amount of structural defects, which may remain in the pebbles after the fabrication process, and thus it is anticipated that the thermally pre-treated pebbles will have higher radiation stability. Previously, the accumulated $\mathrm{RD}$, such as, $\mathrm{E}^{\prime}$ centres $\left(\mathrm{SiO}_{3}{ }^{3-}\right.$ and $\left.\mathrm{TiO}_{3}{ }^{3-}\right), \mathrm{HC}_{2}$ centres $\left(\mathrm{SiO}_{4}{ }^{3-}\right.$ and $\left.\mathrm{TiO}_{3}{ }^{-}\right)$, peroxide radicals $\left(\equiv \mathrm{Si} \mathrm{O} \mathrm{O}^{\circ}\right)$ and $\mathrm{Ti}^{3+}$ centres, in the advanced pebbles were annihilated up to $650 \mathrm{~K}[6]$ and it has been expected, that during irradiation with temperatures higher than $500 \mathrm{~K}$, the recombination processes of RD will dominate. Therefore, the formation of thermally stable RP is mainly expected, such as, colloidal lithium $\left(\mathrm{Li}_{n}\right)$ particles, elementary silicon $\left(\mathrm{Si}_{\mathrm{n}}\right)$, molecular oxygen $\left(\mathrm{O}_{2}\right)$, silanol $(\equiv \mathrm{Si} \mathrm{Si} \equiv)$, disilicate $(\equiv \mathrm{Si} \mathrm{O}$ $\mathrm{Si} \equiv)$ and peroxide ( $\equiv \mathrm{Si} \mathrm{O} \mathrm{O} \mathrm{Si} \equiv)$ bonds.

- - -

After irradiation with $5 \mathrm{MeV}$ accelerated electrons up to $100 \mathrm{MGy}$ absorbed dose at 500-1120 K, a colour change of the advanced $\mathrm{Li}_{4} \mathrm{SiO}_{4}$ pebbles was observed and the pebbles turned grey or black. Most likely, this effect is related to the formation and accumulation of optically active RD and $\mathrm{RP}$, such as, $\mathrm{F}^{+}$and $\mathrm{F}^{00}$ centres (localised electrons in oxygen vacancies), $\mathrm{Lin}$ particles etc. During irradiation at elevated temperatures, the radiolysis of the primary phase and the secondary phase can be expected to cause recrystallization and grain growth. However, major changes in the p-XRD patterns were not observed after irradiation (Fig. 1) and this effect could be related

to the small radiolysis degree ( ) of $\mathrm{Li}_{4} \mathrm{SiO} 4(1000 \mathrm{MGy}=0.1-1 \mathrm{~mol} \%$ [18]) and $\mathrm{Li}_{2} \mathrm{TiO}_{3}\left(500 \mathrm{MGy}=10^{-3} \mathrm{~mol} \%\right.$ [18]) and the detection limits of this method. The radiolysis degree is the percentage

proportion of the decomposed molecules/ions versus the initial number of molecules/ions before irradiation. The detection limit of the p-XRD analysis depends on several factors (preferred orien-tation, texturing and particle size etc.), nevertheless, the detection 


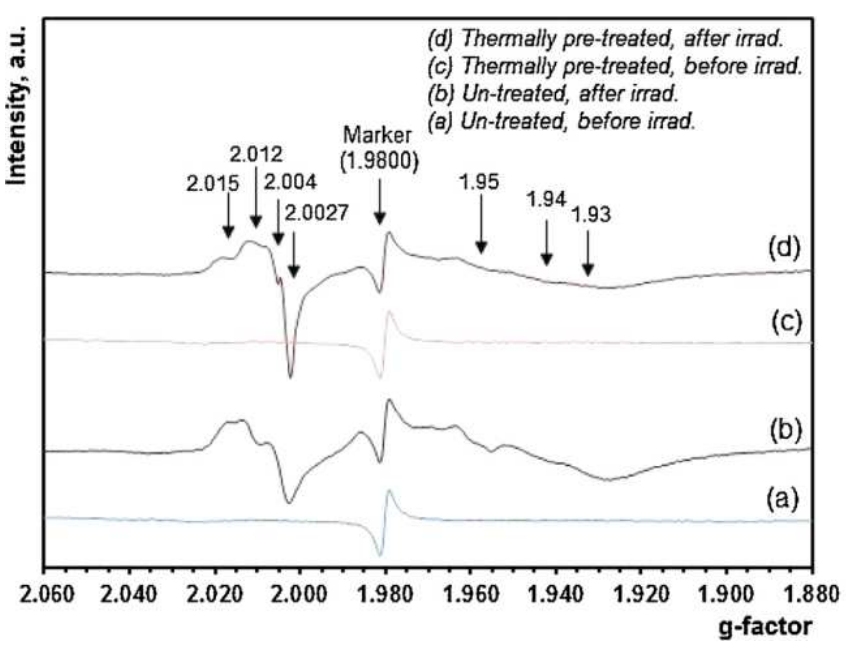

Fig. 2. ESR spectra of the un-treated and thermally pre-treated advanced $\mathrm{Li}_{4} \mathrm{SiO}_{4}$ pebbles with $10 \mathrm{~mol} \% \mathrm{Li}_{2} \mathrm{TiO}_{3}$ before and after irradiation with $5 \mathrm{MeV}$ accelerated electrons up to $100 \mathrm{MGy}$ absorbed dose at $500-1120 \mathrm{~K}$ in a dry argon atmosphere.

limit is typically around $0.1-1$ wt.\% for the samples with a mixed composition.

The ESR spectra of both the un-treated and thermally pre-treated advanced $\mathrm{Li}_{4} \mathrm{SiO}_{4}$ pebbles with $10 \mathrm{~mol} \% \mathrm{Li}_{2} \mathrm{TiO}_{3}$ before and after irradiation are shown in Fig. 2. In the ESR spectra, at least two groups of the first derivative signals were detected. The first group consists of four signals with g-factors from 2.015 to 2.002 , while the second group of three signals is observed from 1.95 to 1.93 . The signals of both groups have a similar shape, $\mathrm{g}$-factor and linewidth to the signals, which were investigated and described in the single phase materials. Therefore, the ESR signals with a g-factor 2.012 \pm 0.001 and $2.015 \pm 0.001$ were assigned to $\mathrm{HC}_{2}$ centres $\left(\mathrm{SiO}_{4}{ }^{3-}\right.$ and $\mathrm{TiO}_{3}{ }^{-}$ ), while the signal with a g-factor of $2.004 \pm 0.001$ was attributed to E' centres $\left(\mathrm{SiO}_{3}{ }^{3-}\right.$ and $\left.\mathrm{TiO}_{3}{ }^{3-}\right)$. Presumably, the narrow ESR signal (singlet, $\mathrm{g}=$ 2.0027, $\mathrm{H}<0.2 \mathrm{mT}$ ) could be asso-ciated with $\mathrm{Lin}$ particles. The overlapping and wide signals with a g-factor from 1.95 to 1.93 might be associated to $\mathrm{Ti}^{3+}$ centres [26].

The $\mathrm{E}$ centres together with $\mathrm{HC}_{2}$ centres are the primary stage electron and hole type $\mathrm{RD}$, while $\mathrm{Lin}$ particles (electron type RP) form in the second and third stage reactions of the radiolysis [19]. The Lin particles form due to the aggregation of electron centers ( $F_{n}$ centers) and the following two kinds of particles may form - the fine particles with size $<1 \mathrm{~m}$ (Lorentz ESR line, $\mathrm{g}$ $=2.0025$ and

$\mathrm{H}<10^{-2} \mathrm{mT}[18]$ ) and coarse particles with a size of 1-10 $\mathrm{m}$ (ESR singlet, $\mathrm{g}=2.0035$ and $\mathrm{H}=10 \mathrm{mT}[18])$. Presumably, the sig-nal of broad Lin particles in the ESR spectra of the advanced pebbles cannot be observed due to overlapping with other signals. The accu-mulated RD and RP in single phase materials, $\mathrm{Li}_{4} \mathrm{SiO}_{4}$ and $\mathrm{Li}_{2} \mathrm{TiO}_{3}$, are stable up to $700 \mathrm{~K}[12,13]$. Therefore, due to the high irradiation temperature $(500-1120 \mathrm{~K})$, the concentration of the accumulated paramagnetic RD and RP in the advanced $\mathrm{Li} 4 \mathrm{SiO} 4$ pebbles is quite small (around $10^{15}-10^{18}$ defects $^{-1}$ ). The total concentration of the accumulated RD and RP was calculated from the ESR results using a double integration method, and the results versus the content of $\mathrm{Li}_{2} \mathrm{TiO}_{3}$ are shown in Fig. 3. The irradiation temperature of the un-treated and thermally pre-treated $\mathrm{Li}_{4} \mathrm{SiO}_{4}$ pebbles with $0,10,20$ and $30 \mathrm{~mol} \% \mathrm{Li}_{2}$ $\mathrm{TiO}_{3}$ during the third irradiation cycle is compa-rable (range: 770-900 K) and thus these pebbles can be compared with each other. While, the detected concentration of paramagnetic RD and RP in the advanced pebbles with 25 and $40 \mathrm{~mol} \% \mathrm{Li}_{2} \mathrm{TiO}_{3}$ is slightly higher in comparison with other pebbles, most likely due to the smaller irradiation temperature in the last irradiation cycle $(500-540 \mathrm{~K})$, and thus these results were not included in Fig. 3.

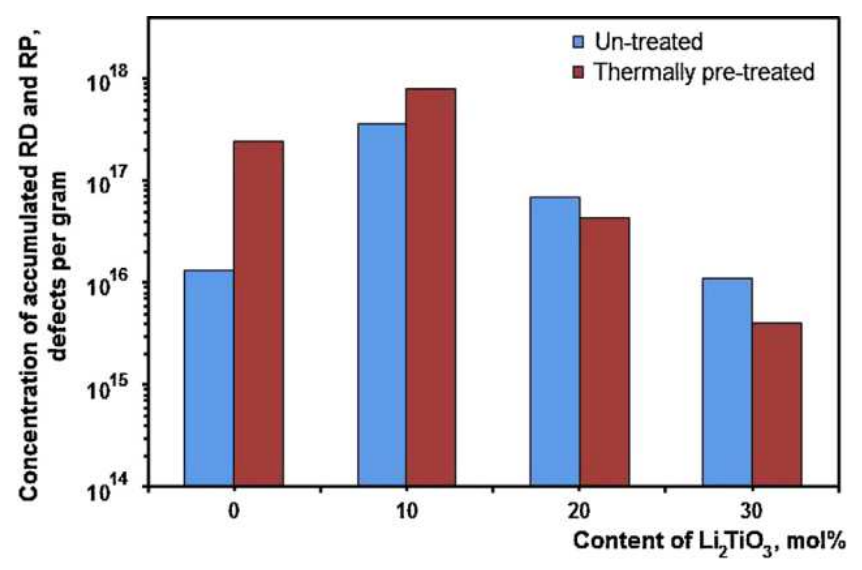

Fig. 3. The total concentration of accumulated paramagnetic RD and RP in the un-treated and thermally pre-treated $\mathrm{Li}_{4} \mathrm{SiO} 4$ pebbles with different contents of $\mathrm{Li}_{2} \mathrm{TiO}_{3}$ after irradiation with $5 \mathrm{MeV}$ accelerated electrons up to $100 \mathrm{MGy}$ absorbed dose at $500-1120 \mathrm{~K}$ in a dry argon atmosphere.

A previous irradiation study [6] already confirmed that the irra-diation temperature has a significant impact on the formation and accumulation of paramagnetic $\mathrm{RD}$ and $\mathrm{RP}$ in the advanced $\mathrm{Li} 4 \mathrm{SiO}_{4}$ pebbles. Therefore, the minor changes in the concentration of the accumulated RD and RP in the untreated and thermally pre-treated pebbles could be attributed to the differences in the irradiation temperature. Nevertheless, $\mathrm{Li}_{2} \mathrm{TiO}_{3}$ has a smaller decomposition degree and radiation chemical yield of $\mathrm{RD}$ than $\mathrm{Li}_{4} \mathrm{SiO}_{4}$ [18], and thus with increasing content of $\mathrm{Li}_{2} \mathrm{TO}_{3}$ as a secondary phase, the concentration of accumulated RD and RP in the advanced pebbles decreases. It has been assumed that the slight increase of accumu-lated RD and RP in the advanced pebbles with $10 \mathrm{~mol} \% \mathrm{Li}_{2} \mathrm{TiO}_{3}$ in comparison with the reference pebbles $\left(0 \mathrm{~mol} \% \mathrm{Li}_{2} \mathrm{TiO}_{3}\right)$ could be related to the structural defects (cracks, open and closed pores), which may form during the fabrication process due to the density differences between the liquid and the crystallised state.

To supplement the results of ESR spectrometry, the TSL glow curves and spectra of the advanced and the reference $\mathrm{Li}_{4} \mathrm{SiO}_{4}$ peb-bles were measured. The thermally stimulated recombination of paramagnetic RD and RP in the advanced pebbles have been ana-lysed in the previous research [6] and the correlation between results of the ESR spectrometry and the TSL technique have been detected. During heating, the luminescence emission occurs, due to the recombination reactions between various hole type $\mathrm{RD}$ and electron type RD and RP. The TSL glow curves of the pebbles (heat-ing rate: $5 \mathrm{~K} \mathrm{~s}^{-1}$ ) exhibit similar behaviour consisting of four peaks, three intense peaks at 450 , 510 and $550 \mathrm{~K}$ and one weak maxi-mum peaked in the range of 600-773 K regardless of the $\mathrm{Li}_{2} \mathrm{TiO}_{3}$ content (Fig. 4). Additionally, one can appreciate how the presence of $\mathrm{Li}_{2} \mathrm{TiO}_{3}$ practically do not affect to the shape of the TSL glow curves, number and position of peaks and therefore it has been assumed that similar hole-electron recombination processes occur in the advanced pebbles similar to the reference pebbles $(0 \mathrm{~mol} \% \mathrm{Li} 2 \mathrm{TiO} 3)$. No signal was detected when measuring luminescence spectra with CCD camera and spectrometer in TSL peaks (heating rate: $2 \mathrm{~K} \mathrm{~s}^{-1}$ ) as the intensity of emission was below the sensitiv-ity limit of the detection system (TSL signal was observed only with photomultiplier tube connected directly). Previously, in the spectra of the reference pebbles at least two main bands with the maximum around 2.6-2.9 and 3.5-3.7 $\mathrm{eV}$ have been detected [24,27]. The luminescence band with the maximum around $2.6-2.9 \mathrm{eV}$ most likely could be associated with $\mathrm{E}^{\prime}$ centres $\left(\mathrm{SiO}_{3}{ }^{3-}\right)$ [28], while the band with the maximum around $3.5-3.7 \mathrm{eV}$ could be related to $\mathrm{HC}_{2}$ centres $\left(\mathrm{SiO}_{4}{ }^{3-}\right)$ [27]. 

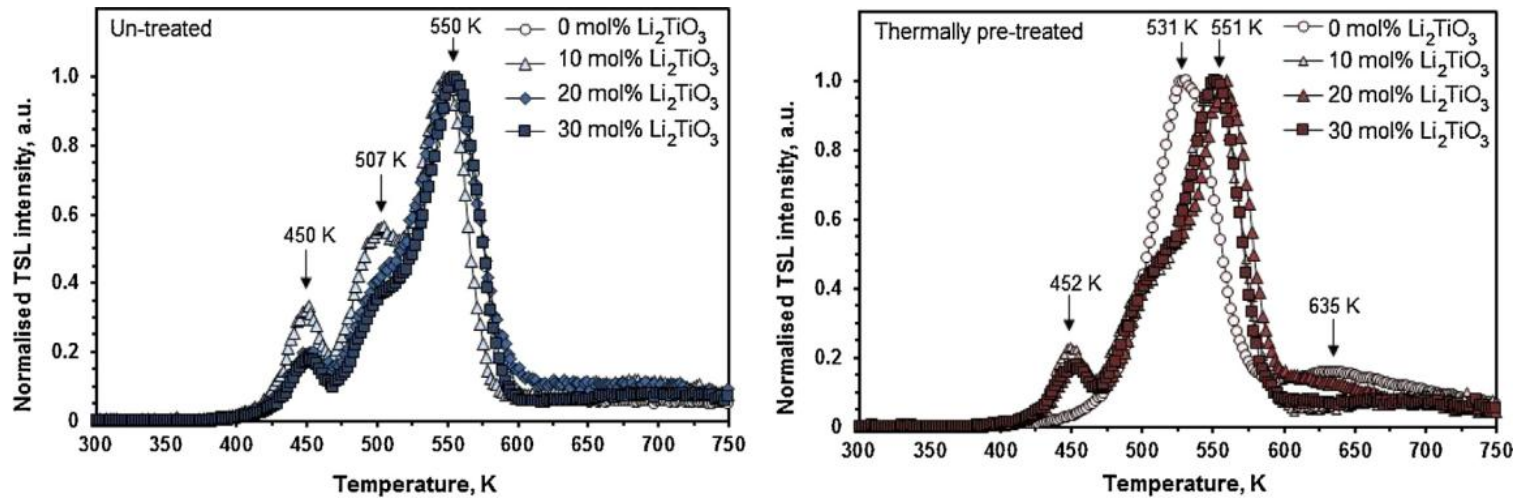

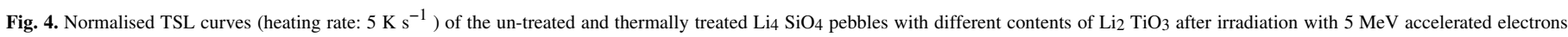
up to 100 MGy absorbed dose at $500-1120 \mathrm{~K}$ in a dry argon atmosphere.

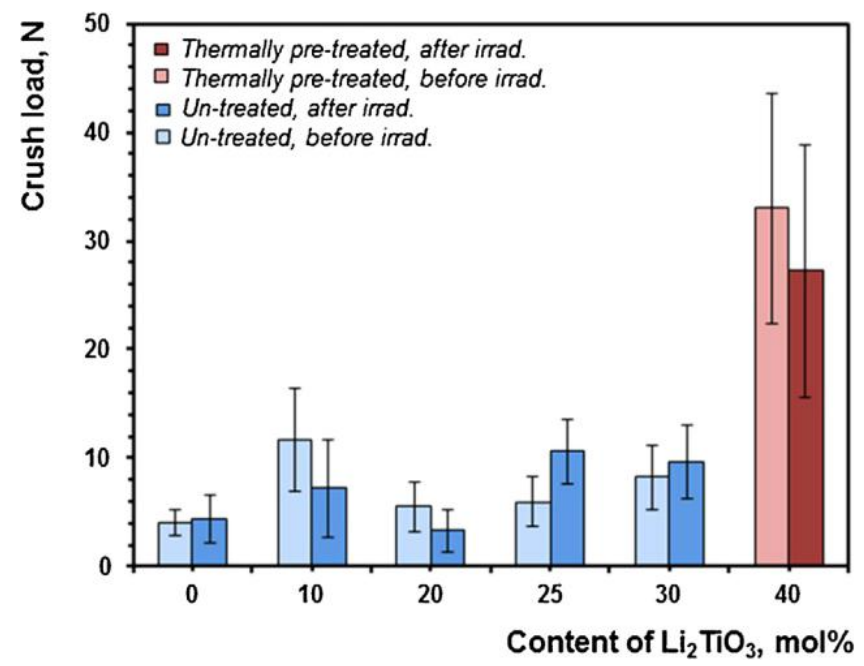

Fig. 5. Average crush load values of the $\mathrm{Li}_{4} \mathrm{SiO}_{4}$ pebbles with different contents of $\mathrm{Li}_{2} \mathrm{TiO}_{3}$ before and after irradiation with $5 \mathrm{MeV}$ accelerated electrons up to $100 \mathrm{MGy}$ absorbed dose at $500-1120 \mathrm{~K}$ in a dry argon atmosphere. The pebbles with $0,20,25$ and $30 \mathrm{~mol} \%$ of $\mathrm{Li}_{2} \mathrm{TiO}_{3}$ have a diameter of $500 \mathrm{~m}$ and the pebbles with 10 and $40 \mathrm{~mol} \%$ of $\mathrm{Li} 2 \mathrm{TiO} 3$ have a diameter of $1000 \mathrm{~m}$.

The high-temperature radiolysis may cause changes to the microstructure of the advanced $\mathrm{Li}_{4} \mathrm{SiO}_{4}$ pebbles, due to the molec-ular oxygen evolution and the formation of micro-pores, cracks and dislocations. Therefore, to complement the results of p-XRD, ESR spectrometry and the TSL technique, the mechanical proper-ties and the microstructure of the advanced $\mathrm{Li}_{4} \mathrm{SiO}_{4}$ pebbles before and after irradiation were studied by uniaxial compressive crush load tests and SEM, respectively. The crush load is dependent on the pebble size [29] and thus only mono-sized pebbles with diam-eters of 500 or $1000 \mathrm{~m}$ were analysed. 40 individual pebbles were used to determine the average crush load for each sample and the results for the $\mathrm{Li} 4 \mathrm{SiO} 4$ pebbles with different contents of $\mathrm{Li}_{2} \mathrm{TiO}_{3}$, both before and after irradiation, are shown in Fig. 5. The advanced pebbles with additions of $10 \mathrm{~mol} \%$ and 40 $\mathrm{mol} \% \mathrm{Li}_{2} \mathrm{TiO}_{3}$ have a diameter $1000 \mathrm{~m}$ and thus, the average crush load values are generally larger. The large standard deviation of the results is very common for ceramics and can be attributed to small dif-ferences in the pebble microstructure including structural defects, minor variations in the pebble size or the composition, as well as different orientations between the sapphire plates during the compression test. It can therefore be said, that the crush load of the pebbles practically does not change after irradiation and the minor differences are within the limits of the standard deviation, however, it is not excluded that these differences could partly also be attributed to the influence of various irradiation temper-atures.

The microstructures of the $\mathrm{Li}_{4} \mathrm{SiO}_{4}$ pebbles with different contents of $\mathrm{Li}_{2}$ $\mathrm{TiO}_{3}$, which were analysed by SEM at etched cross-sections before and after irradiation, are shown in Fig. 6. The chemical compositions of the pebbles are given in the upper row. In the reference pebbles $\left(0 \mathrm{~mol}_{\%} \mathrm{Li}_{2} \mathrm{TiO}_{3}\right)$, the dendritic $\mathrm{Li}_{4} \mathrm{SiO}_{4}$ phase is displayed in a dark grey colour with inclusions of light grey grains of $\mathrm{Li}_{2} \mathrm{SiO}_{3}$. On the other hand, in the advanced peb-bles with content up to $25 \mathrm{~mol} \% \mathrm{Li}_{2} \mathrm{TiO}_{3}$, light grey grains of the secondary phase are very small and homogeneously distributed as inclusions between the $\mathrm{Li} 4 \mathrm{SiO}_{4}$ dendrites, which appear dark-grey. For the advanced pebbles with 30 and $40 \mathrm{~mol} \% \mathrm{Li}_{2} \mathrm{TiO}_{3}$, it can be seen that the lighter $\mathrm{Li}_{2} \mathrm{TiO}_{3}$ phase is the dominant crystal, taking a clear dendritic shape. In this case, the $\mathrm{Li}_{4} \mathrm{SiO}_{4}$ phase fills in the gaps between the $\mathrm{Li}_{2} \mathrm{TiO}_{3}$ dendrites, indicating a reverse in the crystallisation order. As expected from the results of the crush load test, the microstructure of the advanced pebbles after irradi-ation is only slightly changed. After irradiation, agglomeration of pores and cracking, due to the high irradiation temperature, can be seen. Nevertheless, it can be concluded that the advanced peb-bles after irradiation maintain a microstructure comparable to the non-irradiated pebble.

On the basis of the obtained results, it can be concluded that the advanced $\mathrm{Li} 4 \mathrm{SiO}_{4}$ pebbles with different contents of $\mathrm{Li}_{2} \mathrm{TiO}_{3}$ main-tain a comparable radiation stability with the reference pebbles after the simultaneous action of 5 $\mathrm{MeV}$ accelerated electron beam (up to $10 \mathrm{MGy} \mathrm{h}^{-1}$ ) and high temperature (up to $1120 \mathrm{~K}$ ) in a dry argon atmosphere. The additions of $\mathrm{Li}_{2} \mathrm{TiO}_{3}$ as a secondary phase in the advanced $\mathrm{Li}_{4} \mathrm{SiO}_{4}$ pebbles does not provide new or different RD and RP, which could act as possible tritium scavenger centres, and thus it is expected that the tritium diffusion and release processes will be similar to single phase materials - $\mathrm{Li}_{4} \mathrm{SiO}_{4}$ pebbles and $\mathrm{Li}_{2} \mathrm{TiO}_{3}$ pebbles. The accumulated RD and RP annihilates around 423-773 K and thus it has been suggested that the main tritium release peaks could be expected in this temperature range. The pre-liminary deuterium and tritium release studies $[7,30]$ confirm these assumptions, however additional research on the tritium release from the advanced pebbles is required to evaluate the applicability of the breeder pebbles.

\section{Conclusion}

The advanced $\mathrm{Li}_{4} \mathrm{SiO}_{4}$ pebbles with different contents of $\mathrm{Li}_{2} \mathrm{TiO}_{3}$ were examined before and after the simultaneous action of $5 \mathrm{MeV}$ accelerated electron beam (dose rate: up to $10 \mathrm{MGy} \mathrm{h}^{-1}$ ) and high 


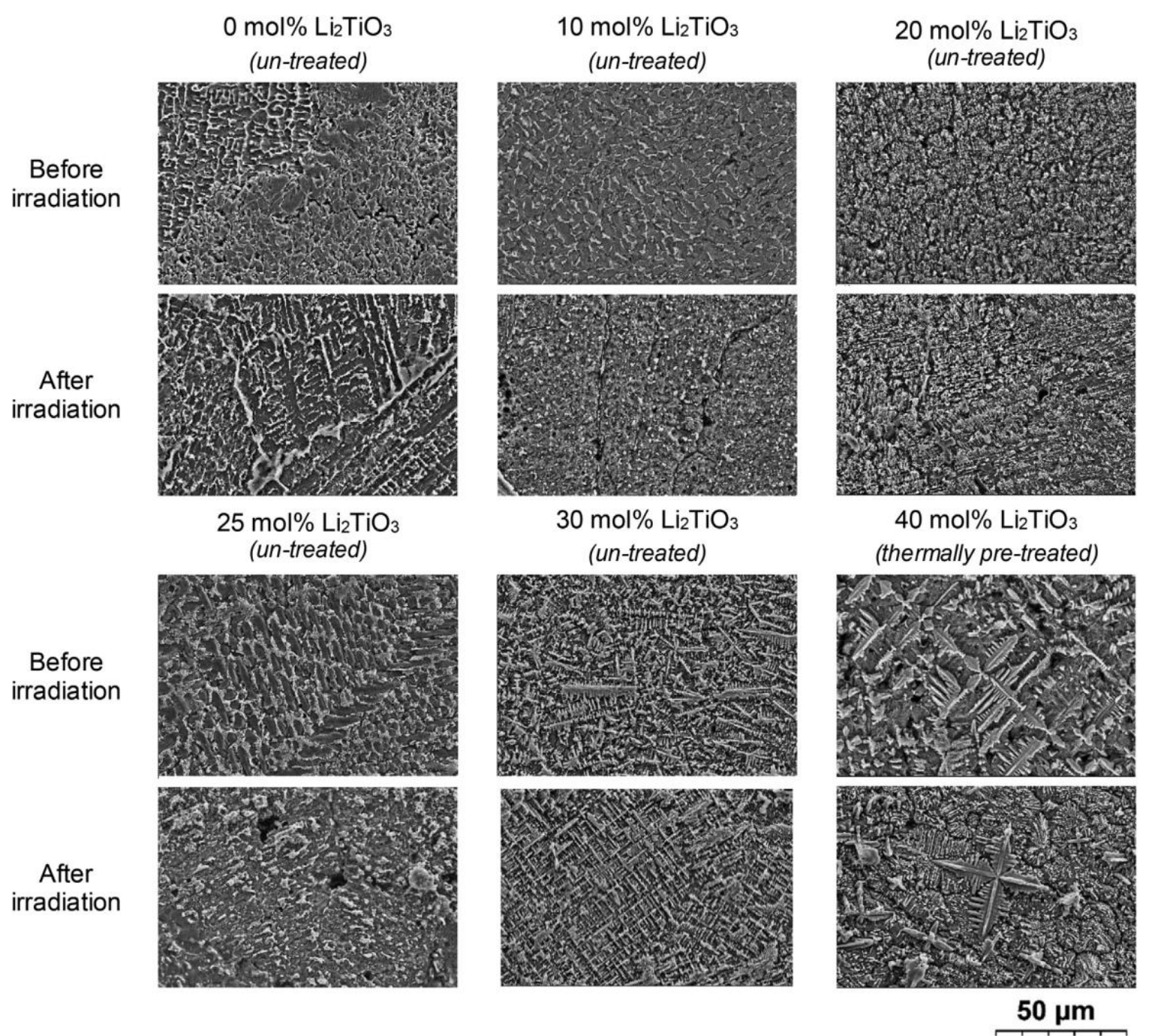

Fig. 6. SEM images of the $\mathrm{Li} 4 \mathrm{SiO} 4$ pebbles with different contents of $\mathrm{Li} 2 \mathrm{TiO} 3$ before and after irradiation with $5 \mathrm{MeV}$ accelerated electrons up to $100 \mathrm{MGy}$ absorbed dose at $500-1120 \mathrm{~K}$ in a dry argon atmosphere.

temperature (up to $1120 \mathrm{~K}$ ) in a dry argon atmosphere. During the irradiation of the advanced $\mathrm{Li}_{4} \mathrm{SiO} 4$ pebbles, the recombination pro-cesses of $\mathrm{RD}$ dominated and the thermally stable RP were mainly accumulated. ESR spectrometry corroborates that in the advanced pebbles, several paramagnetic $\mathrm{RD}$ and RP, which are similar to sin-gle phase ceramics, are accumulated, namely, E' centres $\left(\mathrm{SiO}_{3}{ }^{3-}\right.$ and $\left.\mathrm{TiO}_{3}{ }^{3-}\right), \mathrm{HC}_{2}$ centres $\left(\mathrm{SiO}_{4}{ }^{3-}\right.$ and $\mathrm{TiO}_{3}{ }^{-}$ ), $\mathrm{Lin}$ particles and $\mathrm{Ti}^{3+}$ centres. As well as the irradiation temperature that has a signifi-cant impact on the formation of RD and RP, and with an increasing content of $\mathrm{Li}_{2} \mathrm{TO}_{3}$, the concentration of accumulated paramagnetic RD and RP decreases. The TSL technique confirmed that the accu-mulated RD and RP recombine around 423-773 K. Major changes in the mechanical properties, microstructure and phase composition were not detected after irradiation.

\section{Acknowledgements}

The authors greatly acknowledge the technical and experimen-tal support of O. Valtenbergs and L. Avotina (Institute of Chemical Physics, University of Latvia). The work is performed in the frames of the University of Latvia financed project No. Y9-B044-ZF-N-300, "Nano, Quantum Technologies, and Innovative Materials for Eco-nomics".

\section{References}

[1] R. Knitter, P. Chaudhuri, Y.J. Feng, T. Hoshino, I.-K. Yu, J. Nucl. Mater. 442 (2013) S420-S424

[2] J. Tiliks, A. Vitins, G. Kizane, V. Tilika, E. Kolodinska, S. Kaleja, B. Lescinskis, Fusion Eng. Des. 84 (2009) 1842-1846

[3] S. van Til, A.V. Fedorov, A.J. Magielsen, Fusion Eng. Des. 87 (2012) 885-889.

[4] L.V. Boccaccini, et al., Fusion Eng. Des. 109-111 (2016) 1199-1206.

[5] R. Knitter, M.H.H. Kolb, U. Kaufmann, A.A. Goraieb, J. Nucl. Mater. 442 (2013) S433S436

[6] A. Zarins, et al., J. Nucl. Mater. 470 (2016) 187-196.

[7] M. Gonzalez, E. Carella, A. Morono, M.H.H. Kolb, R. Knitter, Fusion Eng. Des. 98 99 (2015) 1771-1774.

[8] K. Mukai, P. Pereslavtsev, U. Fisher, R. Knitter, Fusion Eng. Des. 100 (2015) 565 570 .

[9] O. Leys, T. Bergfeldt, M.H.H. Kolb, R. Knitter, A.A. Goraieb, Fusion Eng. Des. 107 (2016) 70-74

[10] G. Piazza, A. Erbe, R. Rolli, O. Romer, J. Nucl. Mater. 329-333 (2004) $1260-1265$.

[11] G. Piazza, F. Scaffidi-Argentina, H. Werle, J. Nucl. Mater. 283-287 (2000) 13961400 .

[12] Y. Nishikawa, M. Oyaidzu, A. Yoshikawa, K. Munakata, M. Okada, M. Nishikawa, K. Okuno, J. Nucl. Mater. 367-370 (2007) 1371-1376.

[13] M. Oyaidzu, et al., J. Nucl. Mater. 329-333 (2004) 1313-1317.

[14] G. Kizane, J. Tiliks, A. Vitins, J. Rudzitis, J. Nucl. Mater. 329-333 (2004) $1287-$ 1290

[15] S. Akahori, et al., J. Radiochem. Nucl. Chem. 255 (2003) 257-260

[16] R. Knitter, B. Alm, G. Roth, J. Nucl. Mater. 367-370 (2007) 1387-1392.

[17] D.A.H. Hanaor, M.H.H. Kolb, Y. Gan, M. Kamlah, R. Knitter, J. Nucl. Mater. 456 (2014) 151-161. 
[18] J. Tiliks, G. Kizane, A. Vitins, G. Vitins, J. Meisters, Fusion Eng Des. 69 (2003) $519-522$

[19] J.E. Tiliks, G.K. Kizane, A.A. Supe, A.A. Abramenkovs, J.J. Tiliks, V.G. Vasiljev, Fusion Eng. Des. 17 (1991) 17-20.

[20] V. Grismanovs, T. Kumada, T. Tanifuji, T. Nakazawa, Radiat. Phys. Chem. 58 (2000) 113-117

[21] A. Zarins, G. Kizane, A. Supe, R. Knitter, M.H.H. Kolb, J. Tiliks Jr., Fusion Eng. Des. 89 (2014) 1426-1430

[22] E. Carella, M. Leon, T. Sauvage, M. Gonzalez, Fusion Eng. Des. 89 (2014) $1529-1533$
[23] M. Gonzalez, V. Correcher, J. Nucl. Mater. 445 (2014) 149-153.

[24] E. Feldbach, et al., Nucl. Instr. Meth. B 250 (2006) 159-163.

[25] V. Correcher, M. Gonzalez, Nucl. Instr. Meth. B 326 (2014) 86-89.

[26] P. Lombard, N. Ollier, B. Boizot, J. Non-Cryst. Solids 357 (2011) 1685-1689.

[27] A. Zarins, A. Supe, G. Kizane, R. Knitter, L. Baumane, J. Nucl. Mater. 429 (2012) $34-39$.

[28] K. Moritani, S. Tanaka, H. Moriyama, J. Nucl. Mater. 281 (2000) 106-111.

[29] R.K. Annabattula, M. Kolb, Y. Gan, R. Rolli, M. Kamlah, Fusion Sci. Technol. 66 (2014) 136-141.

[30] M.H.H. Kolb, R. Rolli, R. Knitter, J. Nucl. Mater. 489 (2017) 229-235.

Institute of Solid State Physics, University of Latvia as the Center of Excellence has received funding from the European Union's Horizon 2020 Framework Programme H2020-WIDESPREAD-01-2016-2017-TeamingPhase2 under grant agreement 